\title{
A library spring selection to savour
}

\section{Compiled by Helen Nield}

If you have not tried an ebook please email library@bda.org or call 02075634545 for access details. Members can read these books online at any time or download most titles for up to a week before having to download them again. Visit www.bda.org/ebooks to find more. The library can post books out on loan to you so contact us if you would like to borrow these instead.

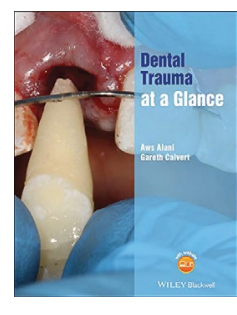

\section{DENTAL TRAUMA AT A GLANCE}

Aws Alani and Gareth Calvert;

2021; Wiley-Blackwell; 96 pp; hard copy only;

ISBN: 9781119562832

'What we both have realised through our daily experiences is the mental trauma that dental injuries can cause our patients. Posttraumatic stress disorder is a real and significant consideration for this patient cohort, and this is an aspect of our care we must not overlook or fail to recognise. Indeed quick, efficient and TIMELY management of dental trauma is likely to reduce the mental anguish and significant comorbidities that may develop in the future...the legacy of poorly managed trauma is long and unrelenting.'

This is the latest of the dental titles in the Wiley-Blackwell at a Glance series and is written by two authors based in the UK. Their decision to write the book was motivated by the fact that dental trauma is unpredictable, both in cause and presentation and with a clinician faced with any number of scenarios a 'quick to refer to' and easily understood text would help in the management of these cases.

Each of the 32 chapters consists of two clearly designed pages, one of figures and the other of text, with the majority finishing with a small box of 'key points'. The authors have, where possible, illustrated the chapters with real clinical examples and illustrations. Chapters cover, amongst other topics: 'Examination of dental trauma, 'Infraction, 'Enamel-dentine fracture, 'Crownroot fracture, 'Features of luxation injuries and principles of repositioning,' 'Principles of splinting', 'Indications for endodontic treatment', 'Management of the immature root', three chapters on different types of root resorption, 'Autotransplantation' and 'The role of orthodontics'. Apart from a very useful index, the book finishes with two appendices; one is a table covering 'Splinting times and follow-up intervals for fracture and displacement injuries in the adult dentition' and the other is a table showing the 'Management of dental trauma in the primary dentition'.

As with the majority of new Wiley-Blackwell publications there is a companion website which includes all of the figures from the book as well as 11 MCQs with the answers included in the questions.

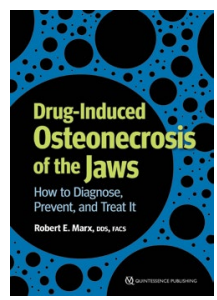

DRUG-INDUCED OSTEONECROSIS OF THE JAWS: HOW TO DIAGNOSE, PREVENT, AND TREAT IT

Robert E. Marx;

2022; Quintessence Publishing; 104 pp; ebook and hard copy; ISBN: 9781647240899

'Dead bone in the mouth, known as drug-induced osteonecrosis of the jaws (DIONJ), is a problem that every dental and oral maxillofacial surgeon faces...the numbers of DIONJ cases have accumulated into tens of thousands and have caused bone loss, infection, pain, and deformity in many individuals...it is hoped that this book will serve as a guide for each provider to lessen the impact of DIONJ on their patients while still maintaining the dental and reconstruction/rehabilitation services we are known to provide.'

This new book by Robert Marx, rather than a new edition of his previous publication, Oral and intravenous bisphosphonateinduced osteonecrosis of the jaws: history, etiology, prevention and treatment does, in fact, look at the disease from a slightly different perspective. Rather than dwelling on the known pathophysiology of DIONJ from each drug, it looks more at measures that a clinician can put in place specifically to, according to the author, 'prevent DIONJ, to assess risk, to slow its progress, to prevent worsening it and to resolve it when it does occur'. Part of that is to look at what questions to ask when taking a medical/dental history and what to look out for on radiographs.

The text is divided into just three chapters: 'Understanding drug-induced osteonecrosis of the jaw', 'Prevention and management of DIONJ in patients treated for osteopenia/ osteoporosis' and 'Prevention and management of DIONJ in cancer patients taking drugs known to cause DIONJ'. The bulk of the book concentrates, therefore, very much on the clinical aspects of DIONJ.

It is worth mentioning that the author has created a staging system for DIONJ which is included in the first chapter along with accompanying photographs. Usefully, the subsequent two chapters each conclude with ten case studies comprising a patient evaluation, suggested course of action and rationale. Finally, the book includes a handy index. 
HANDBOOK OF PEDIATRIC DENTISTRY (5TH EDITION)

Angus Cameron, Richard Widmer (Editors);

2021; Elsevier; 592 pp; ebook and hard copy;

ISBN: 9780702079856

'This... $5^{\text {th }}$ edition, will provide the interested clinician with the information, evidence and support to provide up to date, safe, contemporary paediatric and oral health care - from chairside to the community - and help us address the huge challenges in paediatric oral health not only in your local setting but in all countries and have children's oral health at the forefront of our children's total health.

Eight years on from the previous edition, the Australian editors of this established textbook have produced a thoroughly reviewed and revised new edition with up-to-date information on dental caries, restorative dentistry, special care dentistry, oral medicine, trauma and dental anomalies. Its 29 contributors have been drawn from Australia, America and Europe. The text no longer contains a chapter on orthodontics but four new appendices have been added on paediatric life support, radiology in children, ethics in paediatric dentistry and COVID-19 and paediatric dentistry (written in September 2020). All aspects of clinical paediatric dentistry are covered, as well as a discussion on what paediatric dentistry actually is and two chapters on behaviour management.

There is a plethora of appendices at the end - 16 of them! Apart from those already mentioned, there are useful tables for the Glasgow Coma Scale, growth charts, eruption dates of teeth and common drug usage in paediatric dentistry including dose, frequency, indications and contraindications. The book abounds in clear images, figures and tables but is also a good handy paperback size and easily transportable.

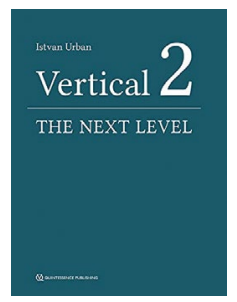

VERTICAL 2: THE NEXT LEVEL OF HARD AND SOFT TISSUE AUGMENTATION

\section{Istvan Urban;}

2022; Quintessence Publishing; 560 pp; ebook and hard copy; ISBN: 9781786981080

'Parts of this book are like watching a surgical video with me, where I stop the video at the most important parts (sometimes frame by frame) and discuss with you, the reader, what I am thinking and doing at that step, and what my next step will be. At the same time, I discuss the reason for each of those steps... the techniques presented here are not overcomplicated - they are simple treatment strategies with lower complication rates and more predictability in the final outcome.'

Istvan Urban's first book, Vertical and horizontal ridge augmentation

- new perspectives was published in 2017. This new book is a continuation of that first title written with the assumption that the reader will have already absorbed the knowledge from the earlier work.

Much of this new book includes step-by-step images of patient cases and as the author looks on it as a combination of atlas and 'show-and-tell', some of the chapters are virtually all images, charts and tables. Some of the cases were not finalised by the time of publication but the finished images can be viewed from a QR code or link within the book.

Just as with the first book, most of the chapters finish with a box comprising 'lessons learned. The contents are divided into ten sections: 'Introduction, 'The extreme vertical defect of the posterior mandible, 'Anterior mandible vertical augmentation', 'Posterior maxilla, 'Anterior maxillary vertical augmentation', Anterior maxillary defect,' 'Soft tissue reconstruction in conjunction with bone grafting, 'Reconstruction of the interimplant papilla,' 'Interproximal bone and soft tissue regeneration' and 'Ultimate esthetics'.

Despite being 160 pages longer than its predecessor, the book lacks an index even though one was included in Urban's first book. Nevertheless, it lives up to the usual standard of Quintessence presentation with good quality images and clear table and diagrams. The hard copy comes in a cloth cover. 